\title{
LOS SANTUARIOS IBÉRICOS. APUNTES PARA EL DESARROLLO DE UNA ARQUEOLOGÍA DEL CULTO
}

\author{
IBERIAN SANCTUARIES. NOTES \\ FOR THE DEVELOPMENT \\ OF A CULT ARCHAEOLOGY
}

\section{LOURDES PRADOS TORREIRA (*)}

\section{RESUMEN}

Se estudian las características especificas de los principales lugares de culto del área ibérica, haciendo hincapié en su emplazamiento y en su relación con el territorio. Se apunta una serie de rasgos comunes a algunos santuarios como su función religiosa, económica y política.

\begin{abstract}
The key features of the main cult places in the Iberian Culture are studied, with a special focus on their location and relationship with the area. Several features shared by some of the sanctuaries, such as their religious, economic and political role, are commented on.
\end{abstract}

Palabras clave: Religión ibérica. Cuevas. Santuarios. Templos. Arqueología del culto.

Key words: Iberian religion. Caves. Sanctuaries. Temples. Cult Archaeology.

$\left(^{*}\right)$ Departamento de Prehistoria y Arqueología. Facultad de Filosofía y Letras. Universidad Autónoma de Madrid. Cantoblanco. 28049 Madrid.

El artículo fue remitido en su versión final el 13-IV-94.

\section{INTRODUCCIÓN}

Durante la pasada década hemos asistido a una revisión y revitalización de los estudios sobre la cultura ibérica. Los nuevos planteamientos han incidido, de una manera particular, en el estudio de los patrones de asentamiento y en la jerarquización del habitat y sus necrópolis. Dentro de toda esta dinámica era necesario buscar también nuevos enfoques en el estudio de la religión ibérica en general. y de sus santuarios en particular.

En primer lugar, falta una aproximación teórica al campo de la religiosidad indígena (Cerri1lo, 1990; Chapa, 1990: 2). La "New Archaeology" incluía en sus pretensiones la posibilidad de penetrar en este campo, como en cualquier otro (Binford, 1968: 21). No obstante, la investigación suele adoptar ante este hecho las dos posturas tradicionales a las que hace referencia Renfrew (1985: 1) en su libro sobre el santuario de Philakopi: rechazo metodológico a su estudio, puesto que supone traspasar los límites de la pura inferencia arqueológica, o bien argumentar que toda aproximación es válida.

Estas mismas actitudes las encontramos con frecuencia reflejadas en el estudio de la religiosidad en época ibérica. A pesar de la extensa bibliografía existente, el conocimiento que poseemos del tema es parcial y fragmentario. Carecemos, por ejemplo, de una visión de con- 
junto de los lugares de culto, que si existe. en cambio. en otras areas geograficas y culturales afines. Ante esta situación parece lógico plantearse cuál pudo ser el papel de la actividad religiosa en la estructura de la sociedad ibérica. Por ello, resulta necesario el desarrollo de una metodología que pueda constituir el soporte adecuado para el estudio de los restos arqueológi$\cos$ de la "actividad religiosa". Estos estudios deben ser precedidos por la identificación de criterios claros para reconocer tales actividades. documentarlas y analizarlas (Pascucci. 199): Cerrillo et alii, 1984).

Entre los problemas de carácter general en el estudio de los santuarios de época ibérica. cabe destacar el hecho de que se trata, en su inmensa mayoría, de yacimientos excavados hace ya muchos años. de los que hemos perdido irremisiblemente información básica acerca de sus contextos arqueológicos. Por otra parte, mu- chos de ellos han proporcionado un numeroso material "artistico" (de manera destacable exvotos en bronce, piedra o terracota), con lo que durante años se ha ofrecido una visión bastante parcial al despreciar el resto de la cultura material.

En la mayoría de los casos tenemos, además. datos muy exiguos de sus restos arquitectónicos. Por último, tampoco hasta el momento se ha establecido con claridad. cuál fué la relación existente entre los poblados y los santuarios y su territorio. Esto dificulta, a su vez, el estudio de las características proto-urbanas o rurales de los lugares de culto. de sus áreas de influencia, así como las causas que pudieran determinar la elección de un lugar como centro sagrado, y si la ocupación del territorio se articulaba a través del carácter religioso del paisaje o si, por el contrario, surge como parte de la ordenación del espacio de estas comunidades.

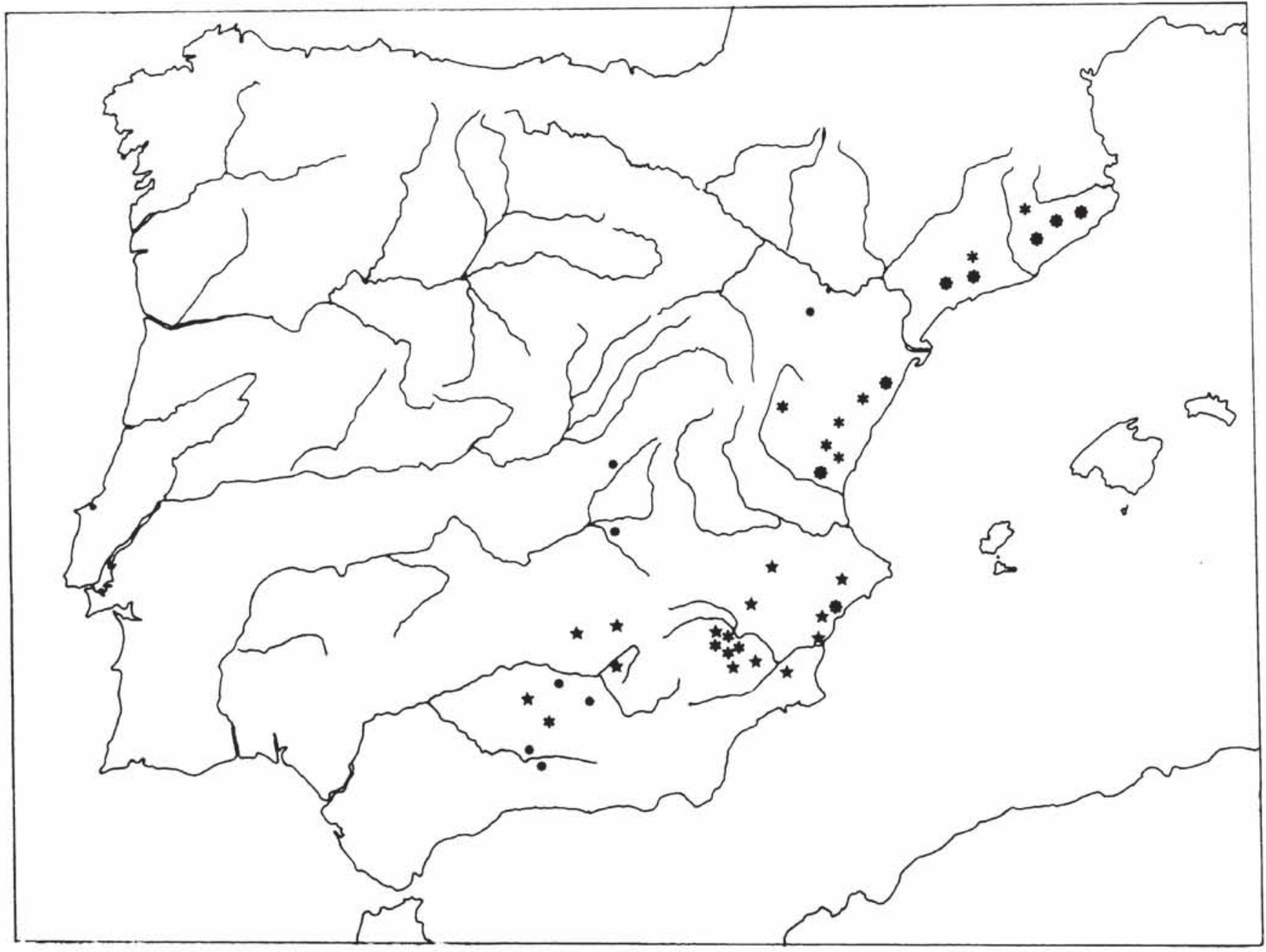

Fig. 1. Principales lugares de culto. Santuarios $\downarrow$ : Templos $\mathbf{k}$; Cuevas $\boldsymbol{*}$; hallazgos aislados 
Intentaré analizar, a continuación. algunas de las características especificas de los principales lugares de culto ibéricos, haciendo hincapié en su emplazamiento y en su relación con el territorio.

\section{PRINCIPALES SANTUARIOS}

No pretendo hacer una clasificación o inventario exhaustivo de todos los centros religiosos de época ibérica (Lucas, 1981: Ruano. 1988), sino intentar ofrecer un panorama general de los principales lugares de culto agrupados por regiones geográficas (Fig. 1).

\section{ANDALUCía}

\section{Santuarios}

Tenemos que referirnos, en primer lugar, a los dos principales santuarios enclavados en la provincia de Jaén, Collado de los Jardines y Castellar de Santisteban. Conocidos sobre todo. por haber proporcionado el mayor número de exvotos de bronce (Fig. 2: 3). Ambos santuarios fueron descubiertos y expoliados a comienzos de siglo. Calvo y Cabré $(1917,1918$ y 1919) excavaron el santuario de Collado de los Jardines y Lantier (1917), por su parte, publicó un estudio muy completo de los materiales que pudo recopilar procedentes de Castellar. Los dos santuarios se caracterizan por estar enclavados en parajes abruptos, en cuevas y junto a fuentes o manantiales.

\section{Collado de los Jardines (Sta. Elena, Jaén)}

Se halla situado en el desfiladero de Despeñaperros oculto entre imponentes riscos. La cueva del santuario se encuentra en la pendiente de la montaña y en sus proximidades surge un manantial. En este lugar realizaron Calvo y Cabré tres campañas de excavaciones en la segunda década del siglo. Los resultados publicados en las memorias de excavación siguen siendo hoy en día nuestra principal, por no decir única, fuente de información a la hora de estudiar este yacimiento.

Las exploraciones en el poblado, ubicado en la cumbre del cerro y comunicado con el santuario por distintos caminos, permitieron descubrir abundantes escorias de metal, así como diversas figuritas de bronce. Este poblado se encontraba amurallado y el santuario quedaría, por consiguiente, extramuros. Lo más interesante del hallazgo de las casas fue la localización de restos de crisoles y de material de fundición relacionados con la fabricación de los bronces. Su cronologia es muy imprecisa aunque, en mi opinión. la producción de exvotos es anterior a la de Castellar (Prados. 1992)

Castellar de Santisteban (Los Altos del Sotillo. Jaén)

A fines de la década de los cincuenta Fernández. Chicarro (1957) llevó a cabo una prospección que no ofreció los resultados esperados. En los últimos años un equipo dirigido por G. Nicolini ha realizado distintas campañas de excavación en el yacimiento. El santuario se compone de un abrigo natural, del que en su momento debió manar agua, donde no se advierten trazas de transformación antrópica, a no ser un sistema de escaleras y rampas excavadas en la roca para permitir el acceso al interior. El santuario plantea problemas de interés, como su origen que, en opinión de Nicolini, arranca por el estilo de algunos exvotos de fines del s. VII y según mis propios estudios representa una tradición tecnológica más evolucionada que la de Collado, lo mismo que su producción (Nicolini, 1969; Prados 1987). Las secuencias estratigráficas obtenidas en las recientes excavaciones parecen documentar una etapa que corresponde a fines del IV o, sobre todo, al s. III a.C. (Nicolini, 1983; Nicolini et alii, 1987). Creo que estas fechas encajan muy bien con algunas características de sus exvotos en bronce, como el hecho de que más del $40 \%$ de los mismos sean esquemáticos; el número mucho más limitado de "tipos" con respecto al santuario de Collado, etc. (Prados, en prensa a, b).

\section{Cástulo (Linares, Jaén)}

Se trata de un complejo, en el asentamiento de la Muela, cerca de Cástulo. La estructura, por el acabado de la construcción -con un magnífico mosaico de guijarros en blanco y negro de fines del s. VII. comienzos del VI a. C.- así como por su ubicación en la orilla del río Guadalimar, ha llevado a que se interprete como un recinto de culto para la práctica de ritos de banquetes, cuyos restos fueron con posterioridad recogidos en una "fosa de consagración" (Blázquez y Valiente, 1981: 202) 

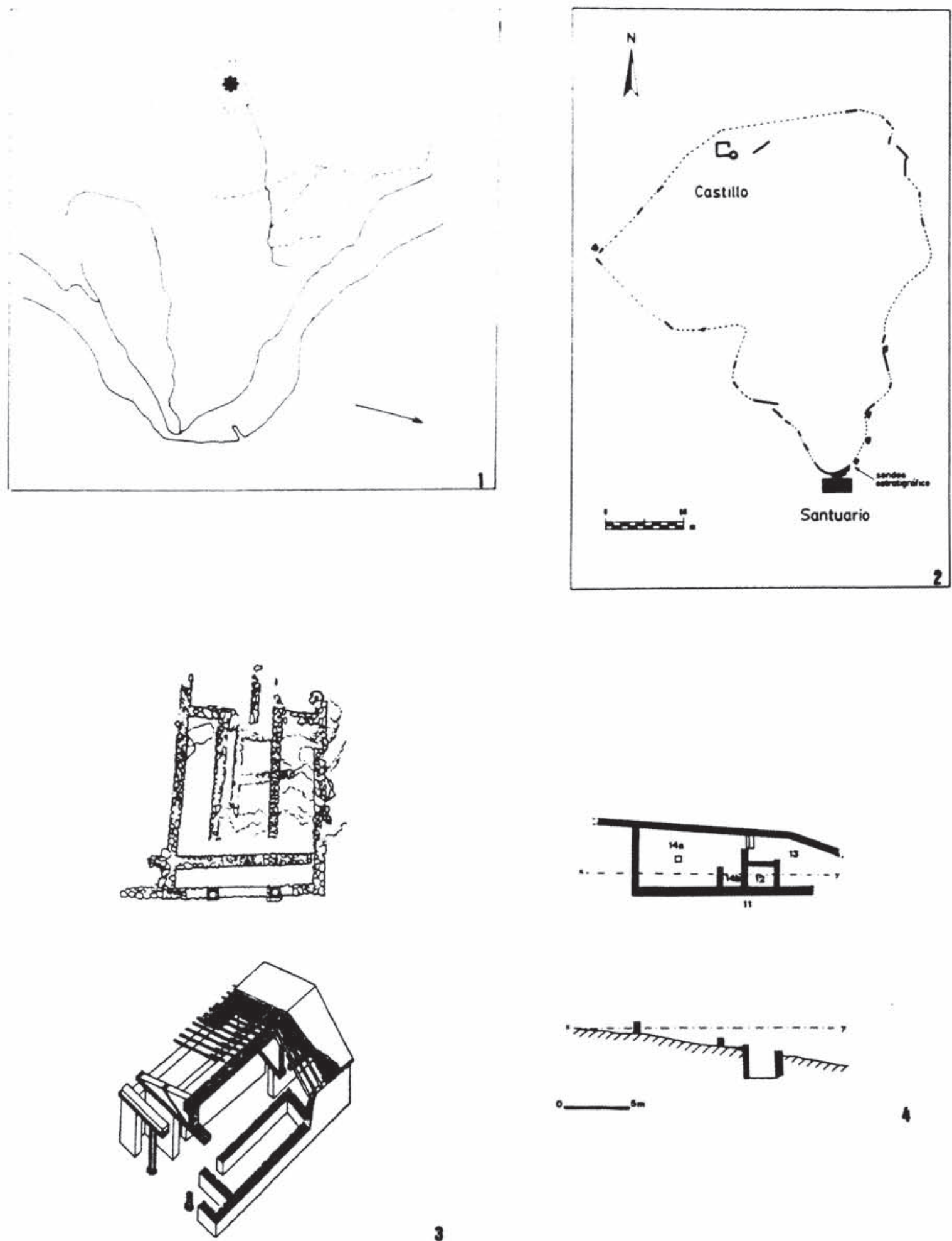

Fig. 2. 1. El Cigarralejo (Mula, Murcia). Situación del Santuario (basado en E. Cuadrado). 2. Torreparedones (Castro del Río-Baena. Córdoba). Delimitación del perímetro amurallado de la ciudad y la zona del santuario (según Morena). 3. Illeta dels Banyets (El Campello, Alicante). Templo A: planta y reconstrucción (según Llobregat). 4. El templo de San Miguel de Lliria: Departamentos 12. 13 y 14 (según Bonet, 1992)

T. P., $51, \mathrm{n}^{\circ} 1,1994$

(c) Consejo Superior de Investigaciones Científicas 
Torreparedones (Castro del Rio-Bacna. (iordoba)

El santuario se encuentra enclavado en un paraje elevado con fuentes manantiales en sus proximidades. La zona estaba densamente poblada y bien comunicada, pues se situaba junto a la vía Obulco-Ulia. El santuario de Torreparedones se halla exactamente en el extremo sur de la ciudad. junto a la muralla. pero extramuros (Fig. 2: 2). La topografía del terreno delata la presencia de un edificio de dimensiones reducidas, aunque de cierta importancia si nos fijamos en algunos fragmentos arquitectónicos. En este promontorio se han recogido superficialmente los exvotos, todos ellos hechos en piedra. El santuario se fecha en el s. II a. C. (Morena, 1989).

\section{Otros hallazgos}

Cabe señalar la presencia de exvotos en otros lugares, como el conjunto de relieves y grabados de équidos procedentes de

Mesa de Luque en Córdoba. El hallazgo plantea la posible existencia de un nuevo santuario ibérico en las cercanías del lugar (Cuadrado y Ruano, 1989). En el mismo caso, bien como

Depósito votivo, bien como santuario sin localizar, se encontraría El Cerro de los Infantes (Pinos Puente, Granada), del que sólo tenemos noticia de la aparición de un gran número de équidos en piedra, sin que existan restos constructivos (Rodríguez Oliva et alii, 1983). O Torre de Benzalá (Torredonjimeno) donde también aparecieron exvotos (Ruano, 1987) y otros posibles lugares de la provincia de Jaén, como sugieren los exvotos de procedencia incierta del Museo de Jaén (Marín Ceballos y Belén, 1987).

\section{Cuevas}

Por último, el hallazgo en superficie de material de época ibérica en la llamada cueva de la Murcielaguina en el término municipal de Priego de Córdoba -entre el que se encuentra una cabecita tallada de piedra caliza-, lleva a plantear la existencia en Andalucía de cuevas santuario similares a las constatadas en Levante (Vaquerizo, 1985).

\section{SUDESTE Y LEVANTE. MURCIA}

\section{Santuarios}

\section{Coimbra del Barranco Ancho (Jumilla)}

El conjunto ibérico de Coimbra del Barranco Ancho lo integran un poblado, un san- tuario y tres necropolss. I a cronología del establecimiento iberice abarea desde finales del s. V a.C. hasta principies del II a.C:

En el santuario. descubierto de forma casual en 1979. se han realizado unicamente prospecciones superficiales que han dado como fruto la localización de una amplia seric de exvotos de terracota en forma de cabezas humanas (Page et alii, 1987: 12, 54).

\section{Recuesto (Cehegin)}

El yacimiento está situado en una colina rocosa de baja altura. Los restos de construcción son casi imperceptibles y los materiales hallados parecen indicar un centro de culto. La cronología, sobre la base de la cerámica ática, se sitúa a fines del s. IV a.C. (Lillo, 1981: 25 y ss.).

\section{Cigarralejo (Mula)}

Excavado por E. Cuadrado en los años 40, se encuentra en las proximidades del pueblo de Mula. El santuario está en la cima del altozano que domina el poblado y la necrópolis, ésta última con más de 400 tumbas excavadas (Fig. 2: 1). Sobre el santuario se edificó una villa romana con varias estancias. El empedrado de un pequeño patio cubría los restos de un muro y una "favissae" que contenía los exvotos, constituídos, casi en su totalidad, por figuras de caballos. Cuadrado fecha el santuario entre los ss. IV-II a.C. (Cuadrado, 1950; Blázquez, 1983).

\section{La Luz (Sta. Catalina del Monte)}

El yacimiento se halla situado en las primeras estribaciones de la Sierra de Carrascoy. El plano general del santuario ha llegado en muy mal estado. Los exvotos se hallaron en la explanada en la que se supone que estaría emplazado el edificio de culto. Ruiz Bremón defiende la existencia de una fuente, que hasta hace pocos años manaba a unos metros del eremitorio de La Luz y que hoy en día ha sido canalizada al interior del convento. La época de máximo apogeo se situaría entre los ss. III y I a. C. (Mergelina, 1924-25; Ruiz Bremón, 1988).

\section{La Encarnación (Caravaca).}

La actual ermita de la Encarnación se encuentra en un altozano, y en sus alrededores apareció una serie de exvotos realizados en caliza local, en su mayoría figuras masculinas, que se han paralelizado con las andaluzas de Torreparedones, Torre de Benzalá y de La Bobadilla (Ramallo, 1993: 122-123). Los sondeos estratigráficos han permitido documentar un mo- 
mento de culto sherico de cronologia imprecisa (entre lo - IV-I a.( .). I.as dos estructuras con. solidadas del cerro corresponden ya a época romana (Ruanoy San Nicolás, 199(); Ramallo, 1993).

\section{Cuevas}

Son varias las localizadas en Murcia, especialmente al Nortc. entre las que podemos citar "La cueva del Calor" y "Peña Rubia”, en Cehegin. "Las canteras". en Calasparra. "Peliciego". en Jumilla, o "La Nariz". en Umbria de Salchite, Moratalla. Esta última ha sido objeto de un estudio detallado por parte de Lillo. Entre los materiales aparecidos en esta cueva destaca la urna denominada "La diosa de los lobos" (Fig. 3: 1). La ocupación se situaría entre los ss. II y I a. C. (Lillo. 1981: 37-43; Rodríguez Alcalde y Chapa, en prensa).

\section{PAÍS VALENCIANO}

\section{Cuevas}

Son muy numerosas y características de esta región las cuevas utilizadas con finalidad religiosa. Podemos destacar La cova de les Dones; Les Maravelles o Villargordo del Cabriel en la provincia de Valencia.

Parece claro el carácter ritual de estos lugares alejados de cualquier poblado. Muchas parecen haber sido utilizadas con este fin a lo largo de un período dilatado de tiempo, desde la Edad de Bronce hasta la Edad Media. Entre sus materiales de época ibérica destacan sobre todo los pequeños vasos caliciformes (Fig. 3: 4). También pueden aparecer fusayolas y huesos de animales. Por su parte, tanto el metal como la cerámica de importacion aparecen muy esporádicamente.

En muchas de ellas debieron utilizar las aguas -sobre todo subterráneas- por su supuesto carácter salutífero. También es frecuente el hallazgo de huesos y vasos cerámicos quemados. Estas cuevas muestran una tendencia a la concentración en zonas con la posibilidad de distintas funciones, sobre todo según algunos autores, dependiendo de la presencia de agua o de estalactitas y estalagmitas (Aparicio, 1976-77; GilMascarell, 1975; Tarradell, 1973; Martí, 1990).

\section{Santuarios}

\section{La Serreta (Alcoy, Alicante)}

El poblado se levanta en lo alto de la sierra de Alcoy, en cuya extremidad más escarpada se erigió el santuario. El poblado vive desde el s.
IV a.C. y no llegó a romanizarse. El santuario, sin embargo, parece que iuvo una larguísima perduración hasta el Bajo Imperio, cuando el habitat habia dejado de existir hacia siglos. Cabe. por tanto, suponer que fue su carácter sacro lo que le hizo prolongar su vida. La mayor parte de sus materiales son exvotos de terracota (Fig. 3: 2). muchos de los cuales representan figuras femeninas. La cronología del santuario se situaria entre los ss. II-I a. C., teniendo su apogeo durante los ss. II-III d. C. (Juan i Moltó, 1987: Llobregat, 1972).

Santa Barbara (Vilavell, Castellón) y Muntanya Frontera (Sagunto, Valencia)

Ambos se hallan localizados en lugares altos. Parecen haber tenido una etapa de fundación pre-augústea y perduran a lo largo de todo el Imperio. Es interesante señalar el posible carácter votivo de las monedas en época romana -muy presentes en ambos yacimientos-, que sustituirian a otras ofrendas de carácter más típicamente indígena. Son frecuentes también los pebeteros. Asímismo, en el Castillo de Guardamar del Segura (Alicante) se plantea la posible existencia de un santuario debido a la abundancia de pebeteros y a la ausencia de otros materiales más característicos de necrópolis o poblados (Abad, 1986).

\section{Templos \\ Illeta dels Banyets (Campello, Alicante)}

Se trata de un conjunto de edificios localizados en el interior del poblado. El primero, el llamado "A" (Fig. 2: 3), es un edificio rectangular con un pórtico con columnas que da acceso a tres cámaras y al fondo aparecen restos de dos cámaras más. En su interior se documentan ánforas y el fragmento de una cabeza masculina. Frente a él, al otro lado de la calle, se localiza un edificio rectangular, compartimentado en cuatro naves y con pequeños espacios al fondo que, por los restos de ánforas y vasijas, se interpreta como el almacén del templo. Separado por otra estrecha calle, hacia el oeste aparece un tercer edificio de culto con planta cuadrada, en el que se ha localizado un altar de perfumes de tipo oriental (Llobregat, 1985).

\section{San Miguel de Liria (Valencia)}

En las últimas publicaciones acerca de este yacimiento se propone que los llamados "Departamentos 12,13 y 14 " de este poblado corresponderían a un recinto sagrado (Fig. 2: 4). No se trataría, por tanto, de una vivienda co- 

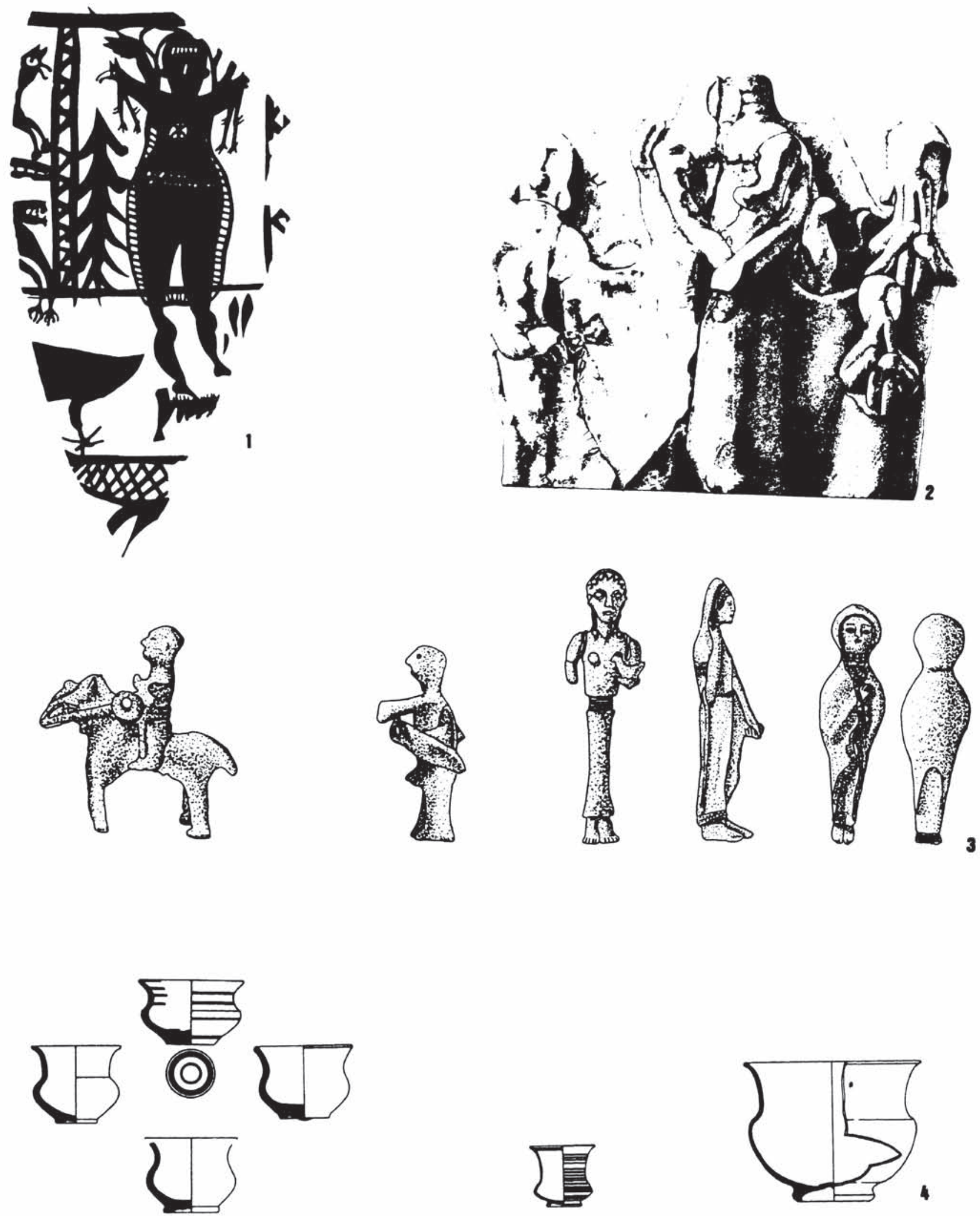

Fig. 3. 1. "La Diosa de los Lobos". Cueva de La Nariz de Salchite (Moratalla. Murcia) (según Lillo). 2. Grupo de terracota de La Serreta de Alcoy (Alicante) (según Blázquez). 3. Bronces procedentes de los santuarios de La Luz (Murcia); Castellar de Santisteban y Collado de los Jardines (Jaén). 4. Vasos caliciformes (según Aranegui y Pla, 1979) 
mun. sno de un templo. atestiguado por la presencia de un "hetilo" en el Departamento 14! un deposito votiso en el 12. De esta forma. se otorga un carácter ritual a los conocidos vasos ceramicos decorados con figuras humanas. yue representan danzas. escenas bélicas. etc (Bonet et alii. $199(1)$.

\section{La Escuera (Alicante)}

Recogemos la posibilidad apuntada por Nïrdstrom (1967) de la existencia de un "edificio de culto" en este lugar. basandose en la espectacularidad de los restos arquitectonicos y en la existencia de huesos y cenizas. Abad (1986) data este vacimiento entre los ss. IV-II a. C.

\section{Capillas domésticas}

Algunos investigadores apuntan la posibilidad de individualizar una serie de espacios cultuales situados en el interior de los asentamientos. con una función claramente diferenciada de los santuarios o templos. Podríamos mencionar los "departamentos 1 y 14 ". del Puntal dels LLops, con concentración de cabezas votivas. lucernas, etc: o el "Departament 2" de Castellet de Bernabé , con un hogar ritual cuadrado (Bonet et alii, 199()), o el de la propia Alcudia de Elche (Lucas, 1981: 246-247: Ramos y Ramos, 1976: 20-24)

\section{CATALUÑa \\ Cuevas}

Son varias las cuevas localizadas en Cataluña que han podido ser utilizadas con fines rituales. Se diferencian de las valencianas en que suelen estar constituídas por una sola sala, en la que penetra la luz exterior sin dificultad. Asimismo se diferencian por su cultura material. ya que en Cataluña encontramos vasos típicamente indígenas, como los "kalathos", y en muy poca proporción vasos pequeños de tipo caliciforme, y escasa cerámica de importación (de la Vega, 1987: Ruano, 1988).

\section{Templos}

Se trata de importantes edificios, siempre en el interior de los oppida, que han sido clasificados por sus excavadores como templos. Podemos destacar, por ejemplo, los llamados "templos de Ullastret", uno de los cuales muestra dos columnas in antis en el pórtico; o el de "Molí d'espigol" de Tornabous (Maluquer, 1986). En Alorda Park" (Calafell), Barcelona, se ha documentado un edificio fechado a fines del s.V y durante el IV a.C., que no parece ser una estructura doméstica, ya que en su interior se documentó un área de ofrendas rituales depositadas en el pavimento, así como un hogar (Sanmarti y Santacana, 1987). Por último, referirnos al vacimiento de La Moleta del Remei en Tarragona. donde se han localizado dos importantes edificios en la zona central del pohlado. fechados a fines del s. V a. C. (Gracia et alit. 1988: 1994).

\section{LA MESETA \\ Santuarios \\ "El Cerro de los Santos" (Montealegre del Cas- tillo. Albacete)}

Se trata del gran santuario del interior. Situado en la vía Heraklea, se encuentra aislado en una pequeña elevación, con restos constructivos muy perdidos. El yacimiento se conoce desde el siglo pasado y a él pertenecen las famosas esculturas en piedra representando figuras masculinas y femeninas de oferentes, cabezas. etc.. que han dado lugar a una extensa bibliografía. Del santuario apenas queda algún resto constructivo, como sillares, cornisas, fragmentos de un capitel, etc. Tampoco se conserva una estratigrafía arqueológica en el lugar, debido tanto a la erosión de los agentes naturales como a la acción antrópica. Su cronología, por tanto, es imprecisa, aunque parece advertirse una destrucción en torno al s. I a. C. (Fernández de Avilés, 1949: Ruiz Bremón, 1985, 1989; Ruano, 1987; Chapa, 1983).

\section{Otros hallazgos \\ El Cabezo de Azaila (Teruel)}

Existe la posibilidad defendida por Cabré, de la existencia de un templo indígena extramuros del que procedería la conocida figura del toro de bronce con la roseta en la frente (Cabré, 1925: 4 y 8). Beltrán (1976: 427), sin embargo, duda seriamente de la entidad del supuesto templo ibérico. Marco Simón (1984: 77), por su parte, apunta la posibilidad de que pudiera tratarse de un culto doméstico.

Cueva del Coscojar (Mora de Rubielos, Teruel)

Las excavaciones realizadas en este yacimiento han sacado a la luz, junto a enterramientos eneolíticos, cerámica ibérica. Se trata de vasijas con ofrendas; de formas caliciformes pequeñas; y páteras, que podrían atestiguar un ritual de libaciones en una cueva-santuario similar a las características del Levante (Marco Simon, 1984: 75-76). 


\begin{abstract}
Alarcos (Ciudad Real)
La aparición de distintos exvotos de bronce. similares a los característicos de los santuarios oretanos, permite apuntar la posibilidad de que en el interior del poblado pudiera haber existido un lugar de culto, no sabemos si doméstico o colectivo. En cualquier caso, tendremos que aguardar a los resultados de las excavaciones en curso (Caballero y Mena, 1987).
\end{abstract}

El Cerrón (Illescas, Toledo)

Fuera del ámbito propiamente ibérico no queremos dejar de señalar la aparición de un relieve realizado en pasta de adobe, al que sus excavadores atribuyen un sentido funerario si bien se localizó en el contexto de una vivienda civil, cuyo significado exacto se nos escapa (Balmaseda y Valiente, 1979 y 1981).

\section{INTENTO DE SISTEMATIZACIÓN}

\section{Las cuevas}

Características, como hemos visto, de todo el área levantina, vemos cómo también empezamos a conocer su presencia en Andalucía.

Las cuevas pueden ser incluídas bajo el término de lugar sagrado de la naturaleza (Edlund, 1987). Es decir, se trataría de lugares cuyas características intrínsecas señalan como sagrados y que son comunes a muchas religiones: montañas, cuevas, bosques, lugares relacionados con agua como ríos, manantiales, etc. En tanto que fenómeno de la naturaleza, las cuevas han sido utilizadas como lugar de habitación, enterramiento o refugio. La presencia de objetos votivos, por tanto, las identifica como lugar sagrado, lo mismo que otros rasgos, como su relación con una fuente o manantial, nos proporcionan su contexto topográfico.

Debido a sus múltiples funciones las cuevas suelen tener un uso continuado, por lo que, en la mayoría de los casos, resulta difícil precisar su cronología.

Su función religiosa estaría vinculada, sobre todo, a pequeñas comunidades, en general, rurales. También se ha de contemplar la posibilidad de que en lugares con agrupaciones de cuevas, cada una de ellas desarrollara una función específica (Rodríguez Alcalde y Chapa, en prensa) y que, algunas de ellas, por sus determinadas características, pudieran ser utilizadas también por una comunidad de ámbito urbano.

\section{Santuarios rurales}

Su origen se hallaría en los lugares que acabamos de mencionar: hosques, rios, etc. Por ello suelen encontrarse en parajes abruptos, próximos a manantiales. o incluso haber surgido a partir de una o varias cuevas. Fueron el foco de desarrollo de futuros santuarios frecuentados, sobre todo en un primer momento, por habitantes de pequeñas comunidades rurales. Con los años evolucionan debido a determinadas características, como su situación en caminos importantes, o por su emplazamiento en una zona rica en recursos naturales.

Con el pasar del tiempo y el desarrollo de estos santuarios, se iría vinculando a ellos una población artesana que podía vivir, en parte y de forma temporal, cuando el ciclo agrícola lo permitiese, de la fabricación de exvotos en serie, que venderían a peregrinos que utilizasen estos santuarios, bien desde poblaciones próximas, bien en su camino hacia otros lugares. Supondría, por tanto, una forma de riqueza añadida al desarrollo del poblado. Prueba de ello, por ejemplo. la tenemos en los restos de crisoles hallados en el poblado de Collado de los Jardines.

Como prototipo de estos santuarios rurales que con posterioridad se desarrollan, tendríamos los ejemplos de Collado de los Jardines y Castellar de Santisteban, en Jaén.

Es posible que algunos santuarios rurales en origen, debido a diversas circunstancias -existencia de importantes recursos económicos, su conexión con cruces de caminos, etc- con el transcurso del tiempo dependieran cada vez más de un centro político.

En el caso concreto de los santuarios de Jaén creo que pudieron controlar también el desfiladero de Despeñaperros en su paso hacia la Meseta y sobre todo ejercer una influencia sobre el área minera. Ruiz y Molinos (1993: 250), por su parte, los consideran santuarios étnico-rurales del grupo oretano.

\section{Santuarios protourbanos}

Es un hecho constatado la aparición y consolidación de los santuarios en las proto-ciudades ibéricas (El Cigarralejo, Verdolay...) cuyo florecimiento se da entre los ss. IV-III a. C. Son santuarios directamente conectados con los poblados.

Suelen situarse inmediatamente al exterior de la muralla del habitat o del límite natural, pero con fácil acceso desde la población, con 
claras funciores rituales de proteccion ! purificacion. El hecho de que en general. se asecen con un manantial o pequeno hosque. explicaria su eleccion. pero siempre como parte del propio desarrollo del sistema proto-urbano. Es decir. los santuarios de este tipo nacerian relacionados con las necesidades ideológicas de la propia estructura protourbana. La presencia de agua no tendría una vinculacion tan directa con la naturaleza como en los santuarios rurales. Posiblemente habría que ponerla en relación con los ritos de purificacion necesarios antes de entrar y salir del oppidum. aunque es muy posible que en determinados momentos. sobre todo en una fase avanzada. a partir del s. III a. C.. su principal función pudiera ser terapeútica. Este uso parece corroborado por la presencia de exvotos anatómicos. y el hecho de que, en muchos casos, se trate de una fuente con depósitos votivos.

En Andalucía podríamos incluir en este grupo el santuario de Torreparedones, fechado en el s. II a. C.. con su clásico emplazamiento extramuros.

El carácter proto-urbano de los principales santuarios murcianos queda reflejado en el triángulo poblado-necrópolis-santuario. Se trataría de santuarios al servicio del oppidum. Es posible que en ellos se adorase a la divinidad protectora del poblado. El hecho, por ejemplo. de que en el Cigarralejo el mayor número de exvotos represente figuras de caballos. podría apoyar este supuesto.

La presencia de santuarios fuera de las ciudades sugiere que había muchas facetas de la cultura urbana que se realizaban fuera de los límites de la ciudad, según prescriben ciertos rituales. Entre ellos destacar los que se refieren a la purificación, protección, expiación, fertilidad y ritos funerarios, cada uno realizado por separado o, en ocasiones, conjuntamente unos y otros. En los santuarios extraurbanos, aquellos más alejados, parece evidente su papel de control de caminos. Se localizan a lo largo de las vías, en puntos de cruce, que podrían relacionarse -como en el mundo etrusco o paleoveneto- con "ritos de paso" comunes a varias religiones: de la vida a la muerte, de la pubertad a la edad adulta, etc (Torelli, 1990; Colonna, 1985; Pascucci, 1990; Capuis, 1991).

\section{Santuarios de ámbito territorial}

Cabe destacar también el posible carácter "político-territorial" de algunos santuarios ex-
Iraurbanos. Apartados de los hahitats principales. podian servir para reunıón de diferentes pucblos con fines politicos y religiosos.

Tenemos el ejemplo del santuario del Cerro de los Santos. Situado en una importante ruta de caminos. equidistante de diversos centros de poblacion. posiblemente en relación con una organización supra-territorial. el santuario podria funcionar como punto de encuentro para sacralizar vinculos entre diversas comunidades (Ruano. 198x). Sería un lugar donde los representantes -y de ahí el carácter elitista del santuario- de las diferentes comunidades pudieran reunirse con fines religiosos políticos y militares, para negociaciones que requiriesen la sanción de los dioses, mediante determinadas prácticas de purificación y sacrificios.

\section{Los templos}

Tradicionalmente se había negado la existencia de éstos. Sin embargo, la aparición de grandes edificios en el interior de los oppida (Campello. Alorda Park, etc), considerados templos por sus excavadores, hizo variar la cuestión. Hoy en día, no obstante, la funcionalidad de estos edificios está de nuevo en revisión. La polémica surgió a raíz de la excavación de lo que primero se interpretó como un gran santuario, "Cancho Roano", en Extremadura (Celestino y Jiménez, 1991 con toda la bibliografía referente a este yacimiento), en un área por tanto no propiamente ibérica y que en la actualidad Almagro-Gorbea (1992) interpreta como un posible palacio orientalizante, siguiendo el ejemplo de los palacios etruscos de Pogio Civitate en Murlo y de Acquarosa en Viterbo. Ruiz y Molinos (1983: 191), por su parte, llegan más lejos al afirmar, respecto a otros edificios singulares (Alorda Park, Tornabous...), que antes de su valoración como templos hay que tener en cuenta la posibilidad de que se tratara de residencias gentilicias. Es muy posible que en los edificios más antiguos esté presente este carácter de residencia gentilicia, aunque también es verdad, como señalan estos mismos autores, que en este mundo aristocrático resulta difícil diferenciar entre lo sacro, y lo privado (Ruíz y Molinos, 1993: 189). Sin embargo, hemos de tener claro que otros muchos edificios, identificados como templos y pertenecientes a una cronología mucho más avanzada, pudieron tener un papel religioso claramente definido. 


\section{Las capillas domésticas}

Por último, quiero referirme a los pequeños recintos sagrados de ámbito doméstico. Su aparición indica una función claramente diferenciada de los santuarios o templos, representantes de la religión oficial. Su utilización estaría vinculada a la práctica de ceremonias de carácter doméstico o familiar.

\section{RECA PITULACIÓN. ASPECTOS GENERALES}

Quiero esbozar algunas cuestiones generales que pueden plantearse a partir del estudio de los santuarios ibéricos.

Parece lógico suponer que la sociedad ibérica desarrollara unos cultos colectivos que permitieran explicar su concepción del mundo, su relación con la naturaleza, sus deseos, esperanzas y angustias. Resulta, sin embargo. muy complejo definir cuándo se producen los primeros indicios de "señalar" o "destacar" lo sagrado en el mundo ibérico. Posiblemente algunos restos exiguos podrían pertenecer a lugares de culto del s. VI a. C. Los santuarios relacionados con la naturaleza, cuevas, bosques, manantiales, etc. pudieron tener un origen anterior al desarrollo de la propia cultura ibérica. Pensemos, por ejemplo, en las pinturas rupestres de la Edad del Bronce próximas a Collado de los Jardines; o en los materiales de diferentes épocas hallados en las cuevas valencianas, etc. Sin embargo. el gran desarrollo de los santuarios tuvo que producirse en un momento más avanzado. Resulta difícil, por no decir imposible, precisar las cronologías sin tener datos fiables de las excavaciones. Por tanto, voy a plantear sólo un hipotético desarrollo de los mismos, centrandome en el caso de los dos santuarios oretanos que conozco más a fondo a través del estudio de sus exvotos en bronce.

Algunos lugares sagrados de la naturaleza pudieron evolucionar por circunstancias diversas y acabar convirtiéndose en santuarios rurales o incluso extraurbanos, con un núcleo de población importante que, en parte, viviera de la riqueza generada por el propio santuario. Este sería el caso de Collado de los Jardines. Posiblemente este santuario se desarrolló a partir del s. V a. C., en principio con un componente aristocrático importante, como demuestra la propia iconografía de un gran número de los exuotos y otras of rendas depositadas. tales como los broches de cinturon. etc. En estos lugares podrian realizarse. entre otros. "ritos de iniciación" (Prados. en prensa b). Con el tiempo. se irian "popularizando". y en ese sentido debemos entender la presencia de los exvotos esquemáticos y anatómicos. Estos últimos irian vinculados al desarrollo de los santuarios salutíferos. siendo también una característica tardía. posiblemente a partir de la Baja Epoca. Castellar. por su parte. representa un desarrollo más tardío y mucho más "provincial" y pobre que el santuario mayor. como demuestra la ausencia de figuras que representen jinetes: una "tipología" mucho más reducida en los exvotos; y por el hecho de que casi la mitad de éstos sean esquemáticos (Prados, en prensa a). Por otra parte, la reanudación en los últimos años de las excavaciones en este yacimiento parecen confirmar esta posibilidad, con un desarrollo del santuario a partir sobre todo del s. III a. C. (Nicolini et alii 1987: Ruiz y Molinos, 1993: 250).

Respecto a la cronología de los llamados "templos" ya se ha señalado también la posibilidad de que algunas de estas edificaciones antiguas, en realidad, pudieran ser residencias gentilicias.

Algunas de las cronologías más precisas nos indican un desarrollo de los santuarios a partir del s. IV (Cigarralejo, La Encarnación, La Escuera), y sobre todo del s. III (Castellar; La Luz...) y del s. II a. C. (Torreparedones, La Serreta...). Por su parte las cuevas -y algunos de los grandes edificios o "templos"-presentan cronologías más imprecisas. Muchos de estos lugares de culto perduran, además, en plena época romana. Vemos, por tanto, cómo se perfila un desarrollo de los lugares de culto, en gran medida, a partir de la Plena Epoca y, sobre todo, de la última fase de la cultura ibérica.

¿Qué funciones podríamos destacar de los santuarios?. En primer lugar hemos de entender algunos de estos lugares, junto con el evidente significado religioso, como auténticos centros económicos. Es posible que ciertos santuarios jugaran un papel relevante en la circulación de la riqueza, como escenario de reconocido prestigio privado, donde el donante ofreciera objetos de lujo -aunque sólo una mínima parte haya llegado hasta nosotros-, como substituto del ámbito funerario. Quizá en este sentido podría analizarse el dato de Quesada (1989) de una menor jerarquización aparente

T. P., $51, \mathrm{n}^{\circ} 1,1994$ 
del ajuar de las necropols en el s. Il a. C.. que para el reflejaria una sociedad mas igualitaria. mientras que (hapa (199()h: 412 ) argumenta que. puesto que en esas fechas el urbanismo de los poblados está ya extraordinariamente desarrollado y que los santuarios se han consolidado desde el s. III a. C.. se trata. por tanto, de una sociedad mucho más compleja que en épocas anteriores. En este sentido encajaria también la hipótesis de Santos (1991: 613) respecto a que un prohable reforzamiento de las formas de vida urbanas en el Sudeste y Levante también lleva consigo el desplazamiento de la amortización de los bienes suntuarios de las necrópolis a los santuarios en forma de exvotos, como ocurre en otras culturas mediterráneas (Colonna. 1985: Torelli y Gros, 1988). Bajo el prisma del poder económico podría entenderse también la posibilidad apuntada por Olmos (1991) de una ruta comercial griega relacionada con los santuarios, defendida por Maluquer (1985) y matizada por Domínguez Monedero (1985: 327. 328 ). Es decir. la función económica quedaría reflejada también al tratarse de centros de desarrollo del comercio o de otra actividad económica importante, que atrajeran mercaderes y con la celebración, incluso, de grandes ferias y mercados. Por otra parte, tampoco debe desdeñarse la posibilidad de que los santuarios administrasen sus propiedades o actuasen como garantes de cambios y transacciones comerciales (Chaves y García Vargas, 1991: 157).

Otro aspecto que cabría destacar respecto a los santuarios sería su dimensión cultural. Se trataría de centros del saber donde pudiera, quizá, desarrollarse la escritura -posibilidad apuntada hace años por Maluquer (1968); o como caja de resonancia de la actividad artística de artesanos que, en algunos casos, se harían venir de lejos.

Tampoco podemos olvidar su dimensión política -señalada ya al hablar del Cerro de los Santos- como lugar cuya principal función fuera permitir a las diferentes comunidades o a sus representantes reunirse con fines políticos y religiosos, para negociaciones que requiriesen la sanción de los dioses (como sabemos que ocurría, por ejemplo, en Fanum Voltumnae).

Por último, queremos destacar, una vez más, las funciones meramente religiosas. Ya hemos visto cómo la presencia del agua es una constante. Es muy normal que la existencia de una fuente o manantial, con buen agua, sea una de las razones por las que los asentamientos se desarrollan en determinados lugares. En muchos casos los santuarios se convierten -o se originanen una fuente con depósitos votivos. Ya hemos señalado su papel en los rituales de purificación antes de entrar al oppidum. También sería clave su presencia en los santuarios terapeúticos. Los aspectos relacionados con la fertilidad quedarían reflejados a través de la iconografía de muchos de los exvotos y ofrendas depositadas en los mismos (Prados, en prensa a).

Los santuarios situados junto -o próximos- a las entradas de los oppida tendrían una función protectora. El significado de los ritos de paso. entendidos de forma global -de la muerte a la vida: de la infancia a la edad adulta, etc.- quedaría patente en muchos de estos santuarios. $Y$ en este sentido, quizá, habría también que ver los santuarios situados en los cruces de los caminos o en las vías de comunicación. Los "ritos de paso" se celebrarían por la necesidad de ser "cruzados" por hombres y ganado, por lo que se exigiría la protección de los mismos y, por tanto, también un ceremonial de "purificación".

Son muchos, y muy sugerentes, los aspectos que se derivan del estudio de los lugares de culto de época ibérica. Sin embargo, nuestro conocimiento de los mismos es tan exiguo que apenas podemos esbozar algunas características generales.

Afortunadamente, pasó ya la época en que los santuarios se veían sólo como lugares que ofrecían "objetos de arte". Por ello, creo que ha llegado el momento en que también en la cultura ibérica pueda desarrollarse un estudio de "los restos arqueológicos de la actividad religiosa" (Pascucci, 1990: 18; Cerrillo et alii, 1984) y, en definitiva, que pueda desarrollarse una arqueología del culto, como preconizaba hace pocos años Renfrew (1985), si bien en relación con todos los aspectos que permitan una mayor comprensión de la sociedad ibérica.

\section{BIBLIOGRAFÍA}

ABAD, L. (1986)a: "Castillo de Guardamar". Arqueología de Alicante 1976-86. Alicante: 151-152.

- (1986)b: "La Escuera. San Fulgencio". Arqueología de Alicante 1976-1986: 146-147.

Almagro Gorbea, M.; Domínguez de la Concha, A. y LOPEZ-AMBITE, F. (1990): "Cancho Ruano. Un palacio orientalizante en la Península Ibérica". Madrider Mitteilungen, 31: 251-308. Maguncia. 
Apari(io Perez, J. (1976-77): "El culto en cuevas en la región valenciana". Homenaje a Garcia Bellido. Revista de la Universidad Complutense. XXV: 9-30. Madrid.

Balmaseda, L. y Val.IENTE., S. (1979): "Excavaciones en el Cerrón (Illescas. Toledo). Noticiario Arqueológıco Hispánico, 7: 153-210. Madrid.

- (1981): "El relieve de Illescas". Archivo Español de Ar. queologia. 54: 215-238.

Beltran Lloris. M. (1976): “Arqueologia e Historia de las ciudades antiguas del Cabezo de Alcalá de Azaila (Teruel)". Librería General. Zaragoza.

BINFORD. L. R. (1968): “Archaeological perspectives". En L. R. y S. R. Binford (eds.): "New perspectives in Ar. chaeology". Chicago. Aldine: 5-32.

BLAZQUEZ. J. M. (1983): "Primitivas religiones ibéricas Religiones prerromanas". II. Ed Cristiandad. Madrid.

Blázquez, J. M. y VAliente, J. (1981): Castulo III. "Excavaciones Arqueológicas en España". 117. Madrid.

Bonet, H.: MATA, C. y Guérin, P. (1990): "Cabezas votivas y lugares de culto edetanos". Verdolav. 2: 185-199. Murcia.

Caballero, A. y Mena, P. (1987): "Los exvotos ibéricos del oppidum de Alarcos". XVIII Congreso Nacional de Arqueología (Islas Canarias, 1985): 615-634. Zaragoza.

CABrÉ, J. (1925): "Los bronces de Azaila". Archivo Español de Arte y Arqueología, I: 297-315. Madrid.

CALvo y CABRE. J. (1917): Excavaciones en la cueva y Co. llado de los Jardines (Sta. Elena, Jaén). Memoria de los trabajos realizados en la campaña de 1916. Junta Superior de Excavaciones y Antigüedades. Madrid.

- (1918): Memoria de los trabajos realizados en la Cam. paña de 1917. Junta Superior de Excavaciones y Antigujedades. Madrid.

- (1919): Memoria de los trabajos realizados en la Campaña de 1918 Junta Superior de Excavaciones y Antigüedades. Madrid.

CAPUIS, L. (1991): "Religiosità veneta e religiosità etrusca. Appunti per una ricerca". Archeologia Classica. XLIII: 1199-1211.

Celestino Pérez, J. y Jiménez Ávil.a, F. (1992): El palacio-santuario de Cancho Roano. IV. El sector Norte. Badajoz.

Cerrillo, E. (1990): “Arqueología de las religiones primitivas y arqueología de las religiones organizadas. Una reflexión". Zephyrus, XLIII: 189-192.

Cerrillo, E.; ONGIL, I. y SAUCEdA, I. (1984): "Religión y espacio, aproximación a una Arqueología de la religión". Arqueología Espacial, 1: 41-54. Teruel.

ColonnA, G. (coord.) (1985): "Santuari d'Etruria". Regione Toscana. Electa. Milán.

CUADRADO DIAZ, E. (1950): Excavaciones en el santuario ibérico del Cigarralejo (Mula, Murcia). Informes y Memorias. Madrid.

Cuadrado, E. y Ruano, E. (1989): "Esculturas de équidos de la colección Alhonoz, Puente Genil (Córdoba)". Trabajos de Prehistoria, 46.: 203-228. Madrid.

ChaPA, T. (1983): "Primeros resultados de las excavaciones en el Cerro de los Santos (Montealegre del Castillo, Albacete). Campañas de 1977-81". XVI Congreso Nacional de Arqueologia (Murcia-Cartagena, 1982): 643-654.
- (lyonl)a: "Algunas consideraciones sobre el estudio de los santuarios ibiricos". Zephyrus. XLIII: 249-251. Sa. lamanca.

- (1990)b: "Recension a F Quesada Sanz. Armamento. guerra y Sociedad en la necropolis ibérica de "El Cabe. caco del Tesoro" (Murcia. España). B.A.R. Intern. Series. 502. Oxford 1989. Trabajos de Pre'historia, 47: $411-412$.

Chaves Tristan. F. y Garcia Varcias. E. (1991): "Reflexiones en torno al área comercial de (iades: Estudio numismático y económico". Gerión. Anejus III. Alimenta. Estudios en homenaje al Dr. Michel Ponsich. Ed. de la Universidad Complutense: 139-16x.

DOMIN(ilez MONEDER(). A. (1985): “Algunas observaciones en torno al "comercio continental griego" en la Meseta meridional". Actas del l Congreso de Historia de Castilla La Mancha. III: 327-334. Ciudad Real.

Edlund. I. E. M. (1987): The Gods and the Place. Location and function of sanctuaries in the countryside of Etruria and Magna Graecia (700-400 B.C.). Skrifter utgivina av svenska. Estocolmo.

FERNÁNDEZ DE AVILÉS, A. (1949): "Las primeras investigaciones del Cerro de los Santos". Boletín de la Sociedad Española de Arte y Arqueología: 57-70. Madrid.

FERNANDEZ ChICARRO, M. C. (1957): “Avance sobre recientes prospecciones arqueológicas en Castellar de Santisteban y Peal del Becerro". Boletin del Instituto de Estudios Giennenses, 13: 153-163. Jaén.

Gil Mascarell. M. (1975): "Sobre las cuevas ibéricas del País Valenciano. Materiales y problemas". Papeles del Laboratorio de Arqueología de Valencia, 11: 281-332. Valencia.

Gracia, F; Munilla, G. y Palarés, R. (1988): La Moleta del Remei, Alcanar-Montsiá. Campañas 1981-86. Tarragona.

JuAN I Molto, J. (1987): “El conjunt de terracotes votives del santuari de la Serreta”. Saguntum, 2: 295-329. Valencia.

LANTIER, R. (1917): El santuario ibérico de Castellar de Santisteban. Memoria 15. Comisión de Investigaciones Paleontológicas y Prehistóricas. Madrid.

Lillo CarPIO, Pedro A. (1981): El poblamiento ibérico en Murcia. Univ. de Murcia. Murcia.

LuCAS, R. (1981): "Santuarios y dioses en la baja época ibérica". Actas de la Asociación Española de Amigos de la Arqueologia: 232 y s.s. Madrid.

Llobregat, E. (1972): "Contestania Ibérica". Instituto de Estudios Alicantinos. Alicante.

- (1985): "Dos temples ibèrics a Yinterior del poblat de l'illeta dels Banyets". Fonaments, 5: 103-112. Barcelona.

Maluquer, J. (1968): "Epigrafía prelatina de la Península Ibérica". Instituto de Arqueología y Prehistoria. Barcelona.

- (1985): "Comercio continental focense en la Extremadura Central". Ceramiques greques i helenistiques a la Peninsula Iberica (Empuries 18-20 Març 1983): 19-25. Barcelona.

- (1986)a: El santuario protohistórico de Zalamea de La Serena, Badajoz. III 1983-1986. Departamento de Prehistoria y Arqueología. Barcelona. 


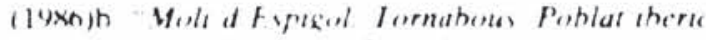
ficneralitat de (atalunva Barcelona

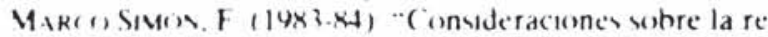
ligiosidad iherica en el ambito turolense". Kalathor. 3. 4: 51.70 . Teruel

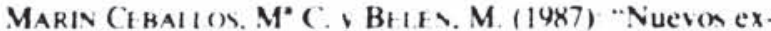
volos ibéricos de la provincia de Jaen". Anales de la Lneversidud de Cadi: ('adil

Maril. M. A. (1990): "Las cuevas del Puntal del Horno Ciego. Villargordo del Cabriel. Valencia“. Saguntum. 22: 141-181. Valencia.

Mrl (iARFS. J. A. (1990): "I in santuario iherico en e campo de Arriba de Archivel. Térmıno municipal de Caravaca (Murcia)". Homenale a J Molina: 16.3-171. Murcia.

Mergelina. C. de (1924-25): El santuario hispano de la Sierra de Murcia. Memoria de las Excavaciones en el eremitorio de Nuestra Señora de La Luz. Junta Superior de Excavaciones y Antigüedades. 77. Madrid

MORENA Lopez. J. L. (1989): El santuario ibérico de To. rreparedones (Castro del Rio-Baena. Córdoba). Diputación Provincial. Córdoba.

Nordstrom. S. (1967): “Excavaciones en el poblado ibérico de La Escuera (San Fulgencio, Alicante)". Valencia.

NicOLINI, G. (1969): “Les bronzes figurés des sanctuaires ibériques.. Presses Universitaires de France. París.

(1983): "La campaigne de fouilles 1981 a Castellar". Mélanges de la Casa de Velazquez. XIX: 443-486. París

Nicolini,G.; Zafra. N. y Ruiz Rodrigitez. A. (1987): "Informe de la Campaña de excavación de 1987 en los Altos del Sotillo (Castellar, Jaén)". Anuario Arqueológico de Andalucia. Sevilla.

Olmos, R. (1991): "Historiografía de la presencia del comercio griego en España". Boletin de la Asociación de Amigos de la Arqueologia, 30-31: 123-133.

Page, V. y Garcia Cano, J. M.: (1987): "I0 años de excavaciones en Coimbra del Barranco Ancho (Jumilla)". Consejería de Educación y Turismo. Murcia.

Pascucci. P. (1990): I depositi votivi paleoveneti. Per un archeologia del culto. Società Archeologica Veneta XIII. Padova.

Prados TORReira, L. (1992): “Exvolos ibéricos de bronce del Museo Arqueológico Nacional". Ministerio de Cultura. Madrid.

- (1988): "Exvotos ibéricos de bronce: aspectos tipológicos y tecnológicos". Trabajos de Prehistoria, 45: 175199. Madrid.

- (1991): "Los exvotos anatómicos del santuario ibérico de Collado de los Jardines (Sta. Elena, Jaén)". Traba. jos de Prehistoria. 48: 313-332. Madrid.

- (en prensa)a: "Los bronces ibéricos, reflejo de la sociedad de su época". Coloquio Internacional Iconografia ibérica e iconografía itálica: Propuesta de interpretación y lectura (Roma 11-13 Noviembre de 1993). C.S.I.C.

- (en prensa)b: "Gesto y comunicación en la toreútica ibérica". La sociedad ibérica en el espejo de su imagen C.S.I.C. Madrid

QUESADA SANZ, F. (1989): Armamento, guerra y sociedad en la necrópolis ibérica de "El Cabecico del Tesoro
(Murcia. España) B A R International Series. 50)? ()xfurd

RAM+111, S $(1493)$ : "La monumentalización de los santuarıos thericos en época tardo-republicana". Ostraka. Russta di antichita I1. 1. Junio: 117-144. Napoles.

Rayos. A. y Ramos. R. (1976): Excavaciones en la Alcudıa de Ellche. Excavaciones Arqueológicas en España. Y1. Madrid

Rt vrRF U. (. (198.5): “The Archaeology of (ult. The Sanctuary at Phulakopy". The British School of Archaeologv at Athens. Londres.

RoDRICil E] AI (AIDH. J. y CHAPA. T. (en prensa): "Meterse en la boca del lobo. Una aproximación a la figura del lobo en la religión ibérica“. Complutum, 4 (en prensa). Madrid.

R(IDRIGIEZ OIINA. P.: PEREgrin Pardo, F. y Anderica FRIAS. J. R. (1983): "Exvotos ibéricos con relieves de équidos en la Vega Granadina" XVI C.N.A. (MurciaCartagena 1982): 751-768. Zaragoza

RI ANO. E. (1987): “La escultura humana de piedra en el mundo ibérico". Ed. La Autora. Madrid.

- (1988): "El cerro de los Santos (Montealegre del CastiIlo. Albacete): Una nueva interpretación del santuario". Cuadernos de Prehistoria y Arqueologia. Universidad Autónoma de Madrid: 253-273. Madrid.

RI ANO, E. y SAN Nicolás, M. (1990): "Exvotos ibéricos procedentes de "La Encarnación" (Caravaca, Murcia)". Homenaje a D. Emeterio Cuadrado Diaz. Verdolay. 2. Murcia.

Rıiz. A. y Molınos. M. (1993): "Los iberos. Análisis arqueológico de un proceso histórico". Ed. Crítica. Madrid.

Ruiz Bremon, M.: (1988): “Aproximación al estudio del santuario ibérico de La Luz”. Archivo Español de Arqueología, 61: 230-244. C.S.I.C. Madrid.

(1989): Los exvotos del santuario ibérico del Cerro de los Santos. Instituto de Estudios Albacetenses. Albacete.

Sanmarti, J. y Santacana. J. (1987): "Un recinte cultual al poblat ibèric d'Alorda Park (Calafell, Baix Penedès)". Fonaments, $6: 157-167$. Barcelona.

Santos VEl.ASCO, J. A. (1991): "Nuevos enfoques y perspectivas en el estudio de las necrópolis ibéricas". Congreso de Arqueología Ibérica. Las necrópolis (U.A.M Noviembre 1992): 607-615. Madrid.

TARRADELL, M. (1979): "Santuaris ibérics ibero-romans a lloc alts". Memoria del Instituto de Arqueologia y Prehistoria de la Universidad de Barcelona. Barcelona

- (1973): "Cuevas sagradas o cuevas santuarios, un aspecto poco valorado de la religión ibérica". Memoria del Instituto de Arqueología y Prehistoria de la Universidad de Barcelona: 25-39. Barcelona

Torelli, M. (1990): Storia degli Etruschi (Cap. VI.4 "LTdeologia religiosa"). Ed. Laterza. Roma-Bari.

TORELli, M. y Gros, P. (1988): "Storia dell' urbanistica. Il mondo romano". Ed. Laterza. Roma-Bari.

VAQUERIZO GIL, D. (1985): “La cueva de la Murcielaguina en Priego-Córdoba, una posible cueva santuario ibérica". Lucentum, IV: 115-124. Alicante.

VEGA, J. de la (1987): "Contribució catalana a l'inventari de les probables coves santuari ibèriques". Fonaments, 6: 171-190. Barcelona.

T. P., $51, \mathrm{n}^{\circ} 1,1994$ 